\title{
FREUD, A RACIONALIDADE MÉDICA E A CONSTITUIÇÃO DO OBJETO PSICOPATOLÓGICO NA PSICANÁLISE: UM ESTUDO EPISTEMOLÓGICO
}

\author{
Kelly Moreira de Albuquerque \\ Universidade de Fortaleza
}

\begin{abstract}
Resumo
Objetivamos investigar o contexto científico da época de Freud, mais especificamente, a racionalidade própria à medicina de seu tempo, quando de suas elaborações teóricas acerca das categorias do normal e patológico. Acredita-se que a elucidação dos modelos da racionalidade médica sobre normalidade e patologia contemporâneos a Freud permite uma compreensão de como ele, Freud, subverteu os aludidos modelos, transgredindo seus cânones teórico-metodológicos fundamentais, para, enfim, ter acesso ao inédito de seu objeto, o inconsciente. Para tanto, iniciaremos pela discussão foucaultiana sobre a descontinuidade entre as racionalidades das medicinas clássica e moderna. Em seguida, caracterizaremos o modelo anátomoclínico preponderante na medicina moderna, mostrando seus efeitos nas construções teóricas em psicopatologia e, numa posição subversiva, na refração freudiana. Freud pensou a doença como fenômeno totalizante, numa perspectiva dinâmica. Foi contra a ontologização da doença que ele se insurgiu. Numa posição antiobjetivista e antirreducionista, ele propôs uma concepção homogênea das perturbações anímicas, redefinindo-as enquanto formas de inserção na linguagem.
\end{abstract}

Palavras-chave: psicopatologia; psicanálise; epistemologia; clínica.

\section{FREUD, THE MEDICAL RATIONALITY AND THE CONSTITUTION OF THE PSYCHOPATHOLOGICAL OBJECT IN PSYCHOANALYSIS: AN EPISTEMOLOGICAL STUDY}

\begin{abstract}
This work aims to investigate the scientific context of Freud's time, more specifically, rationality itself to medicine of his time, when his theoretical elaborations of the categories of normal and pathological. It is believed that the elucidation of the models of medical rationale contemporary to Freud allows an understanding of how it, Freud, subverted the models alluded, violating their fundamental theoretical and methodological canons, to finally have access to unprecedented of its object, the unconscious, radically changing the relationship between the normal and the pathological in the field of psychopathology. To do so, we will start in a Foucaultian perspective, the discussion of the discontinuity between the constituent rationalities of classic and modern medicine. Then characterize the predominant anatomical-clinical model in modern medicine, showing their effects in the theoretical constructs in psychopathology and, a subversive position, the Freudian refraction. Freud thought the disease as a totalizing phenomenon, a dynamic perspective. He was railed the ontologization the disease. In antiobjetivista position, he proposed a homogeneous conception of psychic disturbances, redefining them as forms of subjectivity.
\end{abstract}

Keywords: psychopathology; psychoanalysis; epistemology; clinic.

\section{FREUD, LA RECIONALIDAD MÉDICA, Y LA CONSTITUCIÓN DEL OBJETO PSICOPATOLÓGICO EN EL PSICOANÁLISIS: UN ESTUDIO EPISTEMOLÓGICO}

\begin{abstract}
Resumen
Este trabajo tiene como objetivo investigar el contexto científico de la época de Freud más específicamente, la racionalidad propia de la medicina de su tiempo, cuando sus elaboraciones teóricas de las categorías de normal y patológico. Se cree que el
\end{abstract}


esclarecimiento de los modelos de justificación médica contemporánea Freud permite una comprensión de cómo él, Freud, derrocó a los modelos aludido, violando sus cánones teóricos y metodológicos fundamentales, para finalmente tener un acceso sin precedentes a su objeto, el inconsciente un cambio radical de la relación entre lo normal y lo patológico en el campo de la psicopatología. Para ello, comenzamos por la discusión de Foucault de la discontinuidad entre las concepciones de la medicina clásica y moderna. Luego de caracterizar el modelo anatómico-clínica predominante en la medicina moderna, mostrando sus efectos en los constructos teóricos en psicopatología y en una posición subversiva, refracción freudiano. Freud piensa que la enfermedad como fenómeno tonificación, una perspectiva dinámica. Ontologizacion estaba en contra de la enfermedad que él criticó. En antiobjetivista y antirreducionista posición, propuso una concepción homogénea de las perturbaciones psíquicas, la redefinición de ellos como formas de subjetividad.

Palabras clave: psicopatología; el psicoanálisis; epistemología; clínica.

\section{INTRODUÇÃO}

Este trabalho tem por objetivo investigar o contexto científico da época de Freud, mais especificamente, a racionalidade própria à medicina de seu tempo, quando de suas elaborações teóricas acerca das categorias do normal e patológico. Acredita-se que a elucidação dos modelos da racionalidade médica contemporâneos a Freud permite uma maior compreensão de como ele, Freud, foi capaz de subverter os aludidos modelos, transgredindo seus cânones teóricometodológicos fundamentais, para, enfim ter acesso ao inédito de seu objeto, o inconsciente. Tal ato modificou radicalmente as relações entre o normal e o patológico no campo da psicopatologia.

Este estudo não visa catalogar as influências que atuaram sobre Freud, mas compreender certos assuntos teóricos da medicina da época que permitam tornar inteligível o posicionamento de Freud. De fato, a psicanálise se constitui enquanto área de conhecimento sobre a experiência humana, mais especificamente, sobre os fatos patológicos, pois, é em relação às neuroses e psicoses, que ela se impõe como domínio de conhecimento autônomo em relação à medicina, psiquiatria e psicologia, bem como, aos saberes e práticas culturais.

Por conseguinte, faz-se necessário demarcar que o intuito deste estudo não é trazer acréscimos ao campo analisado, qual seja, as relações entre o estatuto do psicopatológico em Freud e a ciência médica de sua época. Trata-se aqui de uma síntese do que já se tem estabelecido teórica e epistemologicamente sobre o assunto, de uso, pois, didático, endereçada a alunos de graduação.

\section{MÉTODO}

Este trabalho constituiu-se como uma proposta de investigação teórica acerca do trato teórico conferido por Freud as categorias de normal e patológico e das possíveis influências teórico metodológicas da racionalidade médico científica de seu tempo. Primeiramente, será feita, numa perspectiva foucaultiana, pela discussão sobre a descontinuidade entre as racionalidades 
constituintes das medicinas clássica e moderna. Em seguida, caracterizaremos o modelo anátomoclínico preponderante na medicina moderna, mostrando seus efeitos nas construções teóricas em psicopatologia e, numa posição subversiva, os movimentos refratários de Freud em relação a ele. Ora, o modelo anatomopatológico, requerido pela ciência enquanto dispositivo explicativo instituiu uma forma inédita de apreensão do indivíduo e sua doença, fortalecendo a perspectiva organicista do pensamento e, consequentemente a recusa da subjetividade do indivíduo.

\section{RESULTADOS E DISCUSSÕES}

Segundo Prata (1999), a problematização das categorias normal e patológico na psicanálise, convoca-nos a pensar sobre o contexto científico da época de Freud. Certamente, é ele quem fornecerá elementos que tornam possíveis a identificação das condições de possibilidade do discurso freudiano que, como qualquer outro discurso, deve sua emergência a problematização de determinadas questões, possíveis num contexto histórico cultural preciso. De fato:

A psicanálise nasceu com o século $X X(\ldots)$ naturalmente não brotou das rochas nem caiu do céu. Liga-se a coisas anteriores, a que dá prosseguimento; resulta de estímulos que veio a elaborar. Então sua história tem de começar com a exposição das influências que foram decisivas em sua gênese, e não pode esquecer o tempo e as circunstâncias anteriores à sua criação. (Freud, 2011[1924], p. 223).

Como mostra Simanke (2002), a elevação da investigação médica ao status de ciência teve como condição e consequência a "recusa de tudo que concerne à subjetividade do paciente [...] sua redução à condição de objeto" (p.20). Assim, segundo Canguilhem (2010[1966]) as construções teóricas acerca do binômio normal/patológico na medicina de século XIX foram diretamente determinadas por ideais positivistas. Tratou-se do Princípio de Broussais. Este estabelecia uma identidade ontológica entre os fenômenos orgânicos e/ou psíquicos normais e patológicos, sendo as variações apenas de teor quantitativo. Nesta perspectiva, a doença se definia como mudança de intensidade de um estado vital normal, para mais ou para menos. Estas variações de grau entre os fenômenos de saúde e doença não alteram suas essências, que obedecem às mesmas leis de origem e funcionamento. Esta concepção visava negar qualquer diferenciação qualitativa entre o normal e patológico. Vigorava assim uma crença na homogeneidade entre estes fenômenos, que se diferenciariam apenas pela intensidade quantitativa com que se manifestavam. Dito de outro modo, o princípio de Broussais que sustentava na ideia da excitabilidade da matéria viva, aniquilou a diferença de qualidade entre saúde e patologia. Obteve-se assim, um conceito de doença que esvaziava a diferença qualitativa entre saúde e doença, propondo uma curva continua que ia do patológico inferior (doenças designadas 
pelo prefixo 'hipo') ao patológico superior (doenças designadas pelo prefixo 'hiper'). Tal implicava também um estado intermediário ideal que seria a saúde identificada ao conceito matemático e estatístico de norma.

Foucault (2008[1963]) demarcou as condições de possibilidade do princípio de Broussais enquanto aforisma constante na semântica médica do século XIX: o patológico se define pela variação quantitativa, para mais ou para menos em relação ao estado considerado normal. Trata-se aí do modelo anátomoclínico.

Para Foucault (2008[1963]), a medicina dos últimos anos do século XVIII e início do século XIX - por ele denominada medicina moderna - constituiu-se em descontinuidade à chamada medicina clássica, praticada nos séculos XVII e XVIII. Essa transformação, fundamental na arrumação dos saber e prática médicas, não se deveu ao aumento da apropriação teórica e aplicação de técnicas mais eficazes, mas, sobremaneira, a uma reformulação do discurso médico quanto a seus objetos e métodos de investigação. Em relação à doença, passou-se de uma linguagem sem um suporte perceptivo a uma teorização apoiada no contorno nítido daquilo que o olhar permitia ver, graças à experiência da dissecação dos corpos feita por Bichat.

Reconhecendo-se este deslocamento concernente às medicinas clássica e moderna, podemos dizer que a medicina classificatória concebia a doença como essência abstrata que invadia o indivíduo. Nesta perspectiva, a doença era registrada, seja pela catalogação de seus sinais, seja pelos sintomas relatados pelo doente. Concebia-se que este, o indivíduo, hospedava a doença dentro de si. Em contrapartida, na medicina moderna, a afecção passou a ser concebida mediante a ideia um corpo doente. Aqui, a doença tornou-se localizada e nomeada corporalmente, sendo necessário considerar a singularidade do indivíduo. Ocorreu uma transposição da doença para o doente. Com efeito, os postulados sobre a origem das doenças defendidos pela medicina clássica:

[...] foram antes deslocados e como que encerrados na singularidade do doente, na região dos "sintomas subjetivos" que define para o médico não mais o modo do conhecimento, mas o mundo dos objetos a conhecer. O vínculo fantástico do saber com o sofrimento, longe de se ter rompido, é assegurado por uma via mais complexa do que a simples permeabilidade das imaginações; a presença da doença no corpo [...] são tão contestadas em sua objetividade pelo discurso redutor do médico quanto fundados como objetos para seu olhar positivo. As figuras da dor não são conjuradas em benefício de um conhecimento neutralizado, foram redistribuídas no espaço em que se cruzam os corpo e os olhares. O que mudou foi a configuração surda em que a linguagem se apoia, a relação de situação e de postura entre o que fala e aquilo de que se fala. (Foucault, 2008[1963], p. VII).

O fato da doença, na medicina clássica, ser percebida como possuidora de realidade e essência ontológicas próprias, que utilizavam o corpo do indivíduo 
somente como local de manifestação, impedia a atenção à singularidade do indivíduo doente.

Daí se estabelecer uma relação entre anatomia e patologia, entre corpo e doença. Na medida em que a doença passa a ser referida ao corpo, os sintomas deixam de ser considerados a própria doença. Todas as alterações da experiência, como febres, sensação de asfixia, palpitações súbitas, por exemplo, não constituem em si mesmas os fenômenos da doença, mas se referem às condições e às lesões tissulares, construindo um sistema de relações que diz respeito a causas, origens e sedes. A partir da anatomopatologia, todo sintoma clínico deve ser relacionado a uma alteração morfológica. (Pinheiro 2006, p. 49).

Com a introdução do corpo como lugar de origem da doença, pela primeira vez, na história da medicina, as formas singulares do indivíduo foram privilegiadas como objeto de estudo. Foi inclusive esta reorganização que inaugurou a experiência clínica. Esta, por sua vez, nasceu como dispositivo que permitiria a articulação fundamental entre doença e indivíduo. Com efeito, "a clínica [...] deve sua real importância ao fato de ser uma reorganização em profundidade não só dos conhecimentos médicos, mas da própria possibilidade de um discurso sobre a doença" (Foucault, 2008[1963], p. XVI). De fato, sobre o lugar central do corpo na medicina moderna, como mediador da atenção a singularidade, tem-se que:

a problemática da doença, da vida e da morte só pode ser qualificada quando se leva em conta a individualidade orgânica de cada ser vivo. A medida da normatividade, ou seja, capacidade de resistência à morte, é relativa à forma de vida de cada um e às condições do funcionamento orgânico frente às exigências do meio. Nesse sentido, o objeto do saber e da intervenção médica é a existência de cada indivíduo. Em outros termos, a forma de vida só pode ser qualificada tendo em vista que cada caso é um caso. Portanto, o corpo de cada um se torna não só meio de sobrevivência, mas, fundamentalmente, o princípio e o fim da própria existência, na medida em que se sobrepõem corpo saudável e formas adequadas de viver - de querer e ter prazer e de ser livre. (Pinheiro, 2006, p. 51).

Em contrapartida, o modelo anatomopatológico, requerido como critério explicativo para todas as especialidades na medicina moderna, instituindo uma forma inédita de apreensão do indivíduo e sua doença, fortaleceu a perspectiva organicista do pensamento. O emprego irrestrito do organicismo colocou, por sua vez, um impasse para a psiquiatria que, buscando afirmar-se enquanto especialidade médica e, portanto, cientifica, teve que enquadrar seu objeto - a perturbação mental - na medicina orgânica.

Simanke (2002) afirma que mesmo tendo como objeto de estudo o domínio do mental, a psiquiatria precisou aderir ao princípio quantitativo entre o normal e o patológico e, consequentemente, compromissar-se com o modelo organicista, para garantir sua posição no campo das especialidades médicas. Entretanto, tal reducionismo desvalorizou a esfera propriamente psíquica de seu objeto. Parafraseando Lacan, Simanke diz: "sobre o plano psiquiátrico [todo 
dualismo] não pode senão terminar em uma desvalorização das representações" (p.33).

Foi deste modo que Freud (2011[1924]) pôde afirmar que, em seu início, a psicanálise tinha por objetivo compreender o mecanismo de funcionamento das neuroses, superando, desta forma, os insucessos terapêuticos dos médicos. Estes últimos, envolvidos unicamente por aspectos físico-químicos e anatomopatológicos, buscavam localizar a doença neurótica em funções e partes específicas do cérebro. Freud, por sua vez, com a introdução do fator psíquico na compreensão e no tratamento dos estados patológicos, imprimiu-lhes quanto à "cura", uma base racional. Os fatores constituintes de sua teorização acerca da etiologia dos sintomas neuróticos estavam remetidos à "vida emocional (afetividade) e ao jogo das forças psíquicas (dinamismo)". (Freud, 2011[1924], p. 227).

Circunscritos os ideais científicos da época de Freud, quanto às categorias normal e patológico, admitimos que "não é difícil perceber o quanto este desenvolvimento leva a prática médica para longe da psicanalise que, no entanto, dela emerge". (Simanke, 2002, p. 24). Sobre tal emergência, podemos afirmar que:

A psicanálise, é preciso lembrar, ainda que possivelmente revolucionária com sua releitura da sexualidade, estava sendo ainda ousada ao acompanhar a fundação da clínica moderna. Sigmund Freud não somente foi um leitor atento de Claude Bernard, como aliou-se a este vanguardismo para organizar as ideias psicanalíticas originais. [...] Sigmund Freud utiliza claramente o princípio de Broussais, como nos casos das neuroses narcísicas: a observação das psicoses esquizofrênicas Ihe autoriza a postular uma oposição entre libido (objetal) e interesse (libido do Ich). De acordo com seu raciocínio, uma formação patológica deve necessariamente informar a fisiologia (teoria metapsicológica), operando como um experimento que legitima conclusões acerca do normal. Esta leitura do par normalpatológico, presente em Introdução ao narcisismo (1914), visa claramente à constituição da metapsicologia nos moldes da medicina experimental. (Estellita-Lins, 2007, p. 365-66).

Consideramos que as elaborações teóricas de Freud sobre as categorias normal e patológico foram condicionadas por sua inserção no universo epistêmico próprio à medicina moderna. De fato, mesmo sendo contemporâneo dos epistemólogos do positivismo lógico (àqueles do Círculo de Viena), Freud tomou emprestado da medicina clínica moderna uma concepção científica e metodológica de apreensão do psicopatológico. O trecho que se segue ilustra como para Freud, a doença não se constituía como essência autônoma, que invadiria o corpo do indivíduo, mas, referia-se ao próprio indivíduo doente.

Nada vindo de fora penetrou em você; uma parte da atividade da própria mente foi tirada do seu conhecimento e do comando da sua vontade. Isso, também, é porque você está tão enfraquecido em sua defesa; você está utilizando uma parte de sua força para combater a outra parte e é impossível concentrar a totalidade da sua força como você o faria contra um inimigo externo. E nem mesmo é a parte pior 
ou menos importante das suas forças mentais que se tornou, desse modo, antagônica e independente de você. A culpa, sou forçado a dizer, está em você mesmo. (Freud, 2014[1916-17], p. 331).

Assoun (1983, p. 45) diz que Freud foi confrontado com a "querela dos métodos (Methodenstreit)" quando da constituição do saber psicanalítico. Esta, ocorrida em 1883, se caracterizava pela produção de uma discordância em relação ao que devia ser empregado na produção do conhecimento "as ciências da natureza (Naturwissenschaften) e as ciências do espírito (Geisteswissenschaften)". A querela dos métodos pode ser brevemente caracterizada pelos termos "explicar" e "compreender" que correspondiam às "ciências da natureza (Naturwissenschaften)" e às "ciências do espírito (Geisteswissenschaften)", respectivamente. Enquanto as ciências naturais ou nomotéticas reduziam o devir a leis universais que serviam para explicar tanto o particular como o geral, o procedimento das ciências do espírito ou idiográficas, possibilitava apreender o objeto de estudo em sua idiossincrasia, visando compreender o singular sem dissolvê-lo numa lei universal.

Dizendo de outro modo, conforme Assoun (1983), as ciências da natureza atinavam para os juízos de realidade, ao passo que as ciências do espírito implicavam uma valoração. Assim, no momento em que a psicanálise emergiu para a cientificidade, foi convocada a se posicionar ante estas duas perspectivas metodológicas. Freud, então, situou sua psicanálise nas ciências da natureza, afirmando que o dualismo epistemológico não existia, haja vista haver apenas uma só forma de fazer ciência: aquela das ciências naturais.

Assoun (1983) assevera ainda que, para compreendermos a inserção de Freud nas ciências naturais, devemos atentar para o lugar que a interpretação ocupa em seu projeto. De fato, neste, a interpretação não é tomada enquanto uma hermenêutica, na medida em que se funda numa explicação ancorada numa causação semiótica. Com efeito, o fato de a interpretação advir de uma causa, mesmo sendo esta de caráter semiológico, torna pertinente o enquadramento da estrutura metodológica do construto teórico de Freud nas ciências naturais.

Certamente, a interpretação freudiana é "um procedimento intelectual que explica de modo interpretativo ou interpreta fornecendo a causa (Assoun, 1983, p. 49)". Como exemplo, citamos a determinação do sentido do sonho. Esta é feita a partir de uma submissão ao sistema causal em que o que se visa elucidar é o vínculo objetivo entre seus conteúdos manifesto e latente, sendo o primeiro o efeito do segundo, que atua como causa. No campo psicopatológico ocorre o mesmo. A atenção à singularidade do sintoma neurótico não se desamarra de seu determinante. Referindo-nos a Assoun (1983), entendemos que Freud buscou um nexo entre o acontecimento e o processo causal. É este ato freudiano que faz da clínica uma prática objetiva fundada numa causa singular. Freud tomou por sinônimas as categorias ciência e ciências da natureza porque o ideal 
ao qual se alinhou desde o início foi o do campo físico-químico. Este correspondia a suas experiências iniciais com anatomia e fisiologia.

Estellita-Lins (2007, p. 369) reconhece também, faz-se necessário o adendo, que "aquilo que se mostra inadequado para esta metodologia (a lógica da lesão), o fundador da psicanálise vai tomar emprestado da antropologia social, da sociologia ou da arqueologia (e da literatura)". Ora, conforme Beividas (2000): "a psicanalise não poderia embrenhar-se precipitadamente no discurso que mobiliza a ciência quando, a seu ver, trata-se precisamente de denunciar sua infra-patologia de origem" (p.37).

Reconhecemos, também, que Freud foi além da concepção anatomopatológica, que reduzia as perturbações mentais a problemas orgânicos da ordem das degenerescências, inclinações hereditárias e inferioridades constitucionais. Ora, foi tentando transpor uma teorização remetida exclusivamente a etiologias somáticas, anatômicas e químicas, que Freud (2011[1924]) introduziu na concepção das neuroses um método de tratamento psíquico cientificamente formulado. Ele inclusive diz, em relação à psiquiatria que:

[...] o estudo psicanalítico das neuroses pode ser a única preparação para o entendimento das psicoses, que a psicanálise deve possibilitar uma psiquiatria científica no futuro, que não mais se contente em descrever estranhos casos clínicos, evoluções incompreensíveis, e acompanhar a influência de grosseiros traumas anatômicos e tóxicos sobre um aparelho psíquico inacessível a nosso conhecimento. (Freud, 2011[1924], p. 243).

Segundo Simanke (2002), Freud pensou a doença como fenômeno totalizante, numa perspectiva dinâmica. Foi contra a ontologização da doença que ele se insurgiu. Numa posição antiobjetivista e antirreducionista, ele propôs uma concepção homogênea das perturbações anímicas, redefinindo-as enquanto formas de subjetividade. O que estava em jogo aí eram as significações relativas ao sujeito. De fato, Freud inaugurou uma teoria puramente psicológica e histórica das afecções anímicas, que Ihe permitiu embasar sua terapêutica psíquica causal, e não apenas sintomática. Vale destacar que foram justamente as exigências da clínica que fundamentaram a elaboração de sua psicogênese, na medida em que lhe fez confrontar-se com questões eminentemente psicológicas, quando da escuta do relato do sofrimento de suas histéricas. Freud colocou em primeiro plano a dimensão afetiva do psiquismo. Nesta medida:

[...] um dos pontos de ruptura de Freud para com certas concepções da doença mental, contemporâneas aos primeiros passos da formação de uma psicopatologia psicanalítica, consistiu justamente na atribuição de um caráter afetivo a transtornos tidos como puramente intelectuais, por exemplo, as obsessões e, mais significativamente, a paranoia. (Simanke, 2002, p. 51).

Vale salientar, com Simanke (2002), que foi a crença de Freud na impossibilidade do biológico, em explicar determinados fenômenos de ordem 
psíquica, que Ihe permitiu elaborar uma nova concepção do psiquismo. Freud não se absteve de fazer referência aos fenômenos de origem biológica, contudo, reconheceu não poder restringir-se a este campo. Ademais, mediante sua formulação do conceito de pulsão, ele implicou um descentramento radical quanto a toda determinação natural. De fato:

[...] é a própria realidade biológica do homem que priva o orgânico de sua eficácia explicativa. Doravante, nenhuma lesão poderá cavar um buraco maior do que aquele dado desde a origem, que faça diferença para a determinação real dos fenômenos, quer mórbidos, quer normais. (Simanke, 2002, p. 56).

Conforme Simanke (2002), o sujeito advém de sua relação com o Outro justamente porque ele carece de uma determinação biológica eficaz. Daí a formulação de uma teoria do aparelho psíquico que dê conta de um método especifico de investigação dos processos inconscientes. "Uma nova metodologia de análise histórica, psicológica, porém determinista, materialista e concreta que Ihe garantam validade" (p.62). Ernest Jones afirmou, a este respeito:

Sobre a questão de saber se há uma psicologia especial das neuroses Freud responde a Eittingon: "Esta questão convoca duas respostas: sim e não". Se a psicologia geralmente admitida fosse exata, não existiria a necessidade de uma "psicologia especial das neuroses". Porém, no estado atual das coisas, faz-se necessária uma. (Jones, 1953 apud Delrieu, 1997, p. 576).

\section{CONSIDERAÇÕES FINAIS}

À guisa de conclusão apontamos que a psicopatologia em Freud não deve ser encarada como presença de déficit. Sua caracterização das entidades clínicas nos permite remetê-las ao que há de singular no psiquismo. Ocorre aí a destituição do paralelismo entre o déficit capacitário e a lesão orgânica. A estruturação do aparelho psíquico feita por Freud não abandona o caráter determinista e a explicação causal, reforça-os, pois, nesta perspectiva, é possível abarcar aquilo que o determinismo orgânico deixa de fora. Como Assoun (1983) aponta, temos em Freud uma explicação de ordem semiológica. Estendendo a proposição de Ogilvie, apud Simanke, sobre a posição de Lacan em relação a Freud, podemos pensar que Freud construiu "a objetividade do subjetivo" (p.67). Nestes termos, podemos compreender que:

A partir do momento em que se retira das afeç̧ões mentais a referência a um dano orgânico, é quase que obrigatório dar relevo a constituição do aparelho psíquico como um todo, e, mais do que isso, fazer da interpretação o mecanismo fundamental da constituição deste sujeito. Toda a estrutura que forma o aparelho psíquico, seja mórbida ou sadia, deve ser pensada como resultado de uma interpretação da realidade imediata do sujeito. [...] dá-se uma relativização da função normativa da realidade, que vai permitir pensar a psicose como a construção de uma personalidade em bases diferentes das "normais", e não apenas como uma alteração ou um desvio em relação a estas. (Simanke, 2002, p. 64). 
Ao investigar sobre a medida de comparação entre as esferas do normal e patológico que sustentam a teoria psicanalítica constata-se que esta desmantela a oposição radical entre o normal e o patológico presente na racionalidade médica. Freud estabelece uma identidade entre os fenômenos psíquicos a partir da tese de que são realizações de desejo. Nesta perspectiva, as noções de normal e patológico não apontam para polaridades irredutíveis da vivência psíquica. Entre os sonhos, esquecimentos corriqueiros e as paralisias histéricas, por exemplos, têm-se um mesmo sentido da experiência, que diz respeito à subjetividade e não às regularidades orgânicas.

Dito de outro modo, Freud, com a formalização do conceito de inconsciente no campo cientifico, subverteu a concepção de patologia de seu tempo. Ao afirmar que o grau de equivalência entre normalidade e patologia se dá pelo mecanismo de formação (condensação e deslocamento) e por constituírem-se como realizações de desejos, provoca a alteração das relações entre estes dois campos de modo fundamental.

Desta forma, quando insistimos, conforme Assoun (1983), em reconhecer e apontar os modelos epistêmicos que serviram a Freud, mesmo sabendo que ele os ultrapassou, é para conferir maior pertinência e propriedade à sua originalidade. Foi o manejo particular que Freud fez da epistemologia de sua época - movimento contínuo de referência e refração - que possibilitou a apreensão inédita do objeto da psicanálise: o inconsciente. Certamente:

Em nenhum lugar encontra-se mais visível a originalidade freudiana do que na linha imaginária onde ela subverte a linguagem de seu tempo, sem cessar de reconhecê-la como sua, como indica a extraordinária fidelidade de Freud ao dizer de seus mestres confessados e inconfessados. (Assoun, 1983, p. 15).

\section{REFERÊNCIAS}

Assoun, P-L. (1983). Introdução à epistemologia freudiana. Rio de Janeiro: Imago.

Canguilhem, G.(2010). O normal e o patológico. Rio de Janeiro: Forense Universitária. (Originalmente publicado em 1966).

Estellita-Lins, C. E. (2007). Saúde e doença na psicanálise: sobre Georges Canguilhem e Donald W. Winnicott In: B. Bezerra Jr., F. Ortega. Winnicott e seus interlocutores (pp. 340-360). Rio de Janeiro: Relume Dumará.

Foucault, M. (2008). O nascimento da clínica. Rio de Janeiro: Forense Universitária. (Originalmente publicado em 1964).

Freud, S. (2014). Conferências Introdutórias à Psicanálise. Obras Completas, volume 13. São Paulo: Companhia das Letras. (Originalmente publicado em 1916-17).

Freud, S. (2011). Resumo da psicanálise. Obras Completas, volume 16. São Paulo: Companhia das Letras. (Originalmente publicado em 1924). 
PINHEIRO, C V de Q. (2006). Saberes e práticas médicas e a constituição da identidade pessoal. Physis, Rio de Janeiro, 16(1), 45-58. doi: 10.1590/S0103-73312006000100004

PRATA, M R. (1999). O normal e o patológico em Freud. Physis: Rio de Janeiro, $9(1), 37-81$.

Simanke, R. T. (2002). Metapsicologia lacaniana: os anos de formação. São Paulo: Discurso Editorial; Curitiba: Editora UFPR.

Sobre o autor

Kelly Moreira de Albuquerque é psicóloga pela Universidade de Fortaleza, mestre em Psicologia pela Universidade Federal do Ceará e doutoranda em Psicologia da Universidade de Fortaleza. Trabalha como docente no Curso de Graduação em Psicologia da Fanor-Devry Brasil e recebe financiamento de pesquisa do Programa de Suporte à Pós Graduação de Instituições de Ensino Particulares (Prosup/Capes). kellynha.psico@hotmail.com

Recebido em: 28/11/2014 Revisado em: 10/06/2015 Aceito em: 18/06/2015 